\title{
ON THE UNIVALENCE OF A CERTAIN INTEGRAL
}

\author{
BY \\ MAMORU NUNOKAWA
}

1. Introduction. Let $S$ be the class of functions $f(z)$ regular, univalent in $|z|<1$ and normalized by $f(0)=0, f^{\prime}(0)=1$. On the other hand, let $S^{*}$ and $K$ be the subclass of $S$ starlike and convex functions respectively.

It is well known that a function $f(z) \in S$ belongs to $S^{*}$ if and only if

$$
\operatorname{Re}\left(z f^{\prime}(z) / f(z)\right)>0 \text { in }|z|<1
$$

and a function $f(z) \in S$ belongs to $K$ if and only if

$$
1+\operatorname{Re}\left(z f^{\prime \prime}(z) / f^{\prime}(z)\right)>0 \text { in }|z|<1 .
$$

In the recent papers [2], [3], [9], [11], for the univalence of the functions

$$
g(z)=\int_{0}^{z}\left(\frac{f(t)}{t}\right)^{\alpha} d t \text { and } g(z)=\int_{0}^{z}\left(f^{\prime}(t)\right)^{\alpha} d t
$$

was studied.

For instance, the following theorems are obtained in [2], [9], [11].

THEOREM A. If $f(z)$ belongs to $S$ and is close-to-convex, then

$$
g(z)=\int_{0}^{z}\left(f^{\prime}(t)\right)^{\alpha} d t
$$

belongs to $S$ for $0 \leqq \alpha \leqq 1$.

THEOREM B. Suppose $f(z) \in S$ is close-to-convex. Then

$$
g(z)=\int_{0}^{z}\left(\frac{f(t)}{t}\right)^{\alpha} d t
$$

belongs to $S$ for $0 \leqq \alpha \leqq 1$.

THEOREM C. Let $f(z) \in S$ and

$$
g(z)=\int_{0}^{z}\left(\frac{f(t)}{t}\right)^{\alpha} d t .
$$

Then $g(z) \in S$ for $0 \leqq \alpha \leqq\left((1025)^{1 / 2}-25\right) / 100$.

In this paper we improve Theorem $\mathrm{C}$ and others.

Received by the editors April 15, 1969 and, in revised form, June 26, 1969.

Copyright (c) 1969, American Mathematical Society 
2. The main theorems.

LEMMA 1. Let $f(z)=z+a_{2} z^{2}+\cdots$ be regular in $|z|<1$. If $f(z)$ satisfies

$$
1+\operatorname{Re} \frac{z f^{\prime \prime}(z)}{f^{\prime}(z)}>-\frac{1}{2} \text { in }|z|<1,
$$

then $f(z)$ is univalent in $|z|<1$.

We owe this lemma to Ozaki [10], [13].

THEOREM 1. Let

$$
f(z)=z+\sum_{n=2}^{\infty} a_{n} z^{n} \in S^{*}
$$

and

$$
g(z)=\int_{0}^{z}\left(\frac{f(t)}{t}\right)^{\alpha} d t
$$

Then $g(z) \notin S$ for $0 \leqq \alpha \leqq 1.5$ but for $\alpha_{0}<\alpha$, there exists a function $f(z) \in S^{*}$ such that $g(z) \in S$ where $\alpha_{0}$ is the smallest positive root of the equation

$$
\alpha(2 \alpha+1)(\alpha+1)-24=0 .
$$

Proof. It follows that

$$
1+z g^{\prime \prime}(z) / g^{\prime}(z)=1+\alpha\left(z f^{\prime}(z) / f(z)-1\right)
$$

Letting $0<\alpha \leqq 1.5$ we have

$$
1+\operatorname{Re} \frac{z g^{\prime \prime}(z)}{g^{\prime}(z)}=1-\alpha+\alpha \operatorname{Re} \frac{z f^{\prime}(z)}{f(z)}>1-\alpha \geqq-\frac{1}{2} .
$$

Therefore we have that $g(z) \in S$ for $0 \leqq \alpha \leqq 1.5$. On the other hand, if we let $f(z)=z /(1-z)^{2} \in S^{*}$ and $g(z) \in S$, then we must have from [4, p. 2] and [5, p. 134]

$$
g^{\prime}(z)=\frac{1}{(1-z)^{2 \alpha}}=1+2 \alpha z+\frac{2 \alpha(2 \alpha+1)}{2 !} z^{2}+\frac{2 \alpha(2 \alpha+1)(2 \alpha+2)}{3 !} z^{3}+\cdots
$$

and therefore

$$
|2 \alpha| \leqq 2^{2}, \quad\left|\frac{2 \alpha(2 \alpha+1)}{2 !}\right| \leqq 3^{2}
$$

and

$$
\left|\frac{2 \alpha(2 \alpha+1)(2 \alpha+2)}{3 !}\right| \leqq 4^{2}
$$

Letting $\alpha_{0}$ be a positive real number, we must have the following inequality from (1):

$$
0<\alpha \leqq \alpha_{0}<\frac{(73)^{1 / 2}-1}{4}<2
$$


where $\alpha_{0}$ is the smallest positive root of the equation

$$
\alpha(2 \alpha+1)(\alpha+1)-24=0 .
$$

This completes our proof.

THEOREM 2. Let

$$
f(z)=z+\sum_{n=2}^{\infty} a_{n} z^{n} \in K
$$

and

$$
g(z)=\int_{0}^{z}\left(\frac{f(t)}{t}\right)^{\alpha} d t .
$$

Then $g(z) \in S$ for $0 \leqq \alpha \leqq 3$ but for $\alpha_{1}<\alpha$, there exists a function $f(z) \in K$ such that $g(z) \notin S$ where $\alpha_{1}$ is the smallest positive root of the equation $\alpha(\alpha+1)(\alpha+2)-96=0$.

Proof. It is well known [6], [12] that

$$
\operatorname{Re} \frac{z f^{\prime}(z)}{f(z)}>\frac{1}{2} \quad \text { in }|z|<1
$$

Applying the same method as in the proof of Theorem 1 we have

$$
1+\operatorname{Re} \frac{z g^{\prime \prime}(z)}{g^{\prime}(z)}=1-\alpha+\operatorname{Re} \alpha \frac{z f^{\prime}(z)}{f(z)}>1-\alpha+\frac{1}{2} \alpha \geqq-\frac{1}{2}
$$

if $0<\alpha \leqq 3$. Therefore $g(z) \in S$ for $0 \leqq \alpha \leqq 3$.

Putting $f(z)=z /(1-z) \in K$ and $g(z) \in S$, then we have

$$
g^{\prime}(z)=\frac{1}{(1-z)^{\alpha}}=1+\alpha z+\frac{\alpha(\alpha+1)}{2 !} z^{2}+\frac{\alpha(\alpha+1)(\alpha+2)}{3 !} z^{3}+\cdots
$$

and therefore we have also as in the proof of Theorem 1

$$
|\alpha| \leqq 2^{2}, \quad\left|\frac{\alpha(\alpha+1)}{2 !}\right| \leqq 3^{2}
$$

and

$$
\left|\frac{\alpha(\alpha+1)(\alpha+2)}{3 !}\right| \leqq 4^{2} \text {. }
$$

Letting $\alpha$ be a positive real number, we must have from (2) the following

$$
0<\alpha \leqq \alpha_{1}<\left((72)^{1 / 2}-1\right) / 2<4
$$

where $\alpha_{1}$ is the smallest positive root of the equation

$$
\alpha(\alpha+1)(\alpha+2)-96=0 .
$$

This completes our proof and Theorem 2 is a stronger result than $[9$, Theorem 4]. 
THEOREM 3. Let

$$
f(z)=z+\sum_{n=2}^{\infty} a_{n} z^{n} \in K
$$

and

$$
g(z)=\int_{0}^{z}\left(f^{\prime}(t)\right)^{\alpha} d t
$$

Then $g(z) \in S$ for $0 \leqq \alpha \leqq 1.5$ but for $\alpha_{0}<\alpha$, there exists a function $f(z) \in K$ such that $g(z) \notin S$ where $\alpha_{0}$ is the smallest positive root of the equation

$$
\alpha(2 \alpha+1)(\alpha+1)-24=0 .
$$

Proof. We have

$$
1+\frac{z g^{\prime \prime}(z)}{g^{\prime}(z)}=1+\alpha \frac{z f^{\prime \prime}(z)}{f^{\prime}(z)}
$$

and so

$$
\begin{aligned}
1+\operatorname{Re} \frac{z g^{\prime \prime}(z)}{g^{\prime}(z)} & =1-\alpha+\operatorname{Re} \alpha\left(1+\frac{z f^{\prime \prime}(z)}{f^{\prime}(z)}\right) \\
& >1-\alpha \geqq-\frac{1}{2}
\end{aligned}
$$

if $0<\alpha \leqq 1.5$.

Therefore $g(z) \in S$ if $0 \leqq \alpha \leqq 1.5$ and this is a stronger result than [9, Theorem 3].

Putting $f(z)=z /(1-z) \in K$ and $g(z) \in S$, then we have $g^{\prime}(z)=1 /(1-z)^{2 \alpha}$.

By the same reason as in the proof of Theorem 1 we can complete our proof.

THEOREM 4. Let

$$
f(z)=z+\sum_{n=2}^{\infty} a_{n} z^{n}
$$

be regular in $|z|<1, \operatorname{Re} f^{\prime}(z)>0$ and

Then $g(z) \in S$ for $-1 \leqq \alpha \leqq 1$.

$$
g(z)=\int_{0}^{z}\left(f^{\prime}(t)\right)^{\alpha} d t
$$

Proof. It follows that

$$
\operatorname{Re} g^{\prime}(z)=\operatorname{Re}\left(f^{\prime}(z)\right)^{\alpha}>0 \text { in }|z|<1
$$

if $-1 \leqq \alpha \leqq 1$.

By Noshiro [8] we have $g(z) \in S$ for $-1 \leqq \alpha \leqq 1$.

LEMMA 2. Let

$$
f(z)=z+\sum_{n=2}^{\infty} a_{n} z^{n}
$$

be regular in $|z|<1$ and

$$
|\{f, z\}|<\frac{2}{\left(1-r^{2}\right)^{2}}
$$


for all $z,|z|=r<1$, where

$$
\{f, z\}=\left(\frac{f^{\prime \prime}(z)}{f^{\prime}(z)}\right)^{\prime}-\frac{1}{2}\left(\frac{f^{\prime \prime}(z)}{f^{\prime}(z)}\right)^{2}
$$

is the Schwarzian derivative. Then $f(z)$ is univalent in $|z|<1$.

The proof of this lemma can be found in [7].

LEMMA 3. If $f(z)$ is regular in $|z|<1, f(0)=0$ and satisfying $|f(z)|<1$ there, then

$$
\left|f^{\prime}(z)\right|<1 \text { or }\left|f^{\prime}(z)\right|<\frac{\left(1+|z|^{2}\right)^{2}}{4|z|\left(1-|z|^{2}\right)}
$$

according as

$$
|z|<\sqrt{ } 2-1 \text { or } \sqrt{ } 2-1 \leqq|z|<1
$$

These bounds are sharp.

A proof of this lemma can be found in [1].

THEOREM 5. Let

$$
f(z)=z+\sum_{n=2}^{\infty} a_{n} z^{n} \in S
$$

and

$$
g(z)=\int_{0}^{z}\left(\frac{f(t)}{t}\right)^{\alpha} d t
$$

Then $g(z) \in S$ for $0 \leqq \alpha \leqq \alpha_{2}$ where $\alpha_{2}$ is the smallest positive root of the simultaneous equations (5) and

$$
\frac{(18425)^{1 / 2}-75}{800}<\alpha_{2}<\frac{(24841)^{1 / 2}-125}{384} .
$$

Proof. Let $\alpha$ be a positive real number and

$$
F(z)=g^{\prime \prime}(z) / g^{\prime}(z) \text {. }
$$

Then $F(z)$ is regular in $|z|<1$ and we have also from $[9$, p. 396]

$$
|F(z)|<8 \alpha \text { in }|z|<\frac{1}{2} \text {. }
$$

Let

$$
G(z)=\{F(z / 2)-F(0)\} / 10 \alpha \text { in }|z|<1 .
$$

Applying Lemma 3 and the same method as in the proof of [9] we have

$$
\left|G^{\prime}(z)\right|=\frac{1}{20 \alpha}\left|F^{\prime}\left(\frac{z}{2}\right)\right| \leqq \frac{\left(1+\rho^{2}\right)^{2}}{4 \rho\left(1-\rho^{2}\right)} \quad \text { in } \sqrt{ } 2-1 \leqq|z| \leqq \rho<1 .
$$

From the maximum principle we have

$$
\left|F^{\prime}(z)\right| \leqq \frac{5 \alpha\left(1+\rho^{2}\right)^{2}}{\rho\left(1-\rho^{2}\right)} \text { in }|z| \leqq \frac{\rho}{2}
$$


Hence we get

$$
\begin{aligned}
|\{g, z\}| & \leqq\left|\left(\frac{g^{\prime \prime}(z)}{g^{\prime}(z)}\right)^{\prime}\right|+\frac{1}{2}\left|\left(\frac{g^{\prime \prime}(z)}{g^{\prime}(z)}\right)\right|^{2} \\
& =\left|F^{\prime}(z)\right|+\frac{1}{2}|F(z)|^{2} \leqq\left\{32 \alpha^{2}+\frac{5 \alpha\left(1+\rho^{2}\right)^{2}}{\rho\left(1-\rho^{2}\right)}\right\} /\left(1-r^{2}\right)^{2} \quad \text { in }|z|=r \leqq \frac{\rho}{2} .
\end{aligned}
$$

In $\rho / 2 \leqq|z|=r<1$ we have from $[9$, p. 397]

$$
\begin{aligned}
\left|F^{\prime}(z)\right| & \leqq \frac{2 \alpha}{r(1-r)(1-\sqrt{ } r)} \\
& =\frac{2 \alpha(1+r)^{2}(1+\sqrt{ } r)}{r\left(1-r^{2}\right)^{2}} \\
& <\frac{2 \alpha}{\left(1-r^{2}\right)^{2}} \cdot\left\{2\left(1+\frac{\rho}{2}\right)^{2}\left(1+\left(\frac{\rho}{2}\right)^{1 / 2}\right) \rho^{-1}\right\}
\end{aligned}
$$

and

$$
\begin{aligned}
|F(z)| & \leqq \frac{2 \alpha}{r(1-r)} \\
& =\frac{2 \alpha(1+r)}{r\left(1-r^{2}\right)} \\
& <\frac{2 \alpha}{\left(1-r^{2}\right)}\left(1+\frac{2}{\rho}\right)
\end{aligned}
$$

Therefore we have

$$
\begin{aligned}
|\{g, z\}| \leqq & \frac{2 \alpha}{\left(1-r^{2}\right)^{2}}\left\{2(1+\rho / 2)^{2}\left(1+(\rho / 2)^{1 / 2}\right) \rho^{-1}\right\}+\frac{4 \alpha^{2}}{\left(1-r^{2}\right)^{2}}(1+2 / \rho)^{2} \\
& =\left\{4 \alpha^{2}(1+2 / \rho)^{2}+4 \alpha(1+\rho / 2)^{2}\left(1+(\rho / 2)^{1 / 2}\right) \rho^{-1}\right\} /\left(1-r^{2}\right)^{2} \\
& \text { in } \rho / 2 \leqq|z|<1 .
\end{aligned}
$$

\section{Putting}

$$
\begin{aligned}
32 \alpha^{2}+\frac{5 \alpha\left(1+\rho^{2}\right)^{2}}{\rho\left(1-\rho^{2}\right)} & =4 \alpha^{2}(1+2 / \rho)^{2}+4 \alpha(1+\rho / 2)^{2}\left(1+(\rho / 2)^{1 / 2}\right) \rho^{-1} \\
& =2
\end{aligned}
$$

and

$$
\sqrt{ } 2-1 \leqq \rho<1
$$

Let $\alpha_{2}$ be the smallest positive root of the simultaneous equations (5).

Then we have

$$
|\{g, z\}| \leqq \frac{2}{\left(1-r^{2}\right)^{2}} \quad \text { in }|z|=r<1
$$

if $0<\alpha<\alpha_{2}$.

From Lemma 2 we have $g(z) \in S$ for $0 \leqq \alpha \leqq \alpha_{2}$. (For the case $\alpha=0$, Theorem 5 is trivial.) 
It can be verified that

$$
\frac{(18425)^{1 / 2}-75}{800}<\alpha_{2}<\frac{(24841)^{1 / 2}-125}{384} .
$$

RemarK. If we put $\rho=\frac{1}{2}$ in (3) and (4) we have

$$
|\{g, z\}| \leqq \frac{2}{\left(1-r^{2}\right)^{2}} \quad \text { in }|z|=r<\frac{1}{4}
$$

if

$$
0 \leqq \alpha \leqq \frac{(24841)^{1 / 2}-125}{384}
$$

and

$$
|\{g, z\}| \leqq \frac{2}{\left(1-r^{2}\right)^{2}} \quad \text { in } \frac{1}{4} \leqq|z|=r<1
$$

if

$$
0 \leqq \alpha \leqq \frac{(18425)^{1 / 2}-75}{800}
$$

Therefore we have $g(z) \in S$ for at least

$$
0 \leqq \alpha \leqq \frac{(18425)^{1 / 2}-75}{800}
$$

This is an improvement of [9, Theorem 1].

The author would like to acknowledge helpful suggestions made by Professor W. M. Causey.

\section{REFERENCES}

1. C. Carathéodory, Theory of functions of a complex variable, Vol. 2, Chelsea, New York, 1954.

2. W. M. Causey, The close-to-convex and univalence of an integral, Math. Z. 99 (1967), 207-212.

3. P. L. Duren, H. S. Shapiro and A. L. Shields, Singular measures and domains not of Smirnov type, Duke Math. J. 33 (1966), 247-254.

4. P. R. Garabedian and M. Schiffer, A proof of the Bieberbach conjecture for the fourth coefficient, J. Rational Mech. Anal. 4 (1955), 427-465.

5. W. K. Hayman, Multivalent functions, Cambridge Univ. Press, Cambridge, 1958.

6. A. Marx, Untersuchungen über schlichte Abbildungen, Math. Ann. 107 (1932), 40-67.

7. Z. Nehari, The Schwarzian derivative and schlicht functions, Bull. Amer. Math. Soc. 55 (1949), 545-551.

8. K. Noshiro, On the univalency of certain analytic functions, J. Fac. Sci. Hokkaido Univ. Ser. I 2 (1932), 89-101.

9. M. Nunokawa, On the univalency and multivalency of certain analytic functions, Math. Z. 104 (1968), 394-404.

10. S. Ozaki, On the theory of multivalent functions. II, Sci. Rep. Tokyo Bunrika Daigaku 4 (1941), 45-86.

11. W. C. Royster, On the univalence of a certain integral, Michigan Math. J. 12 (1965), 385-387. 
12. E. Strohhäcker, Beiträge zur Theorie der schlichten Funktionen, Math. Z. 37 (1933), 356-380.

13. T. Umezawa, Analytic functions convex in one direction, J. Math. Soc. Japan 4 (1952), 194-202.

\section{GunMa University,}

MAEBASHI, JAPAN 